\title{
Community informatics social e-learning network: a case study of Nigeria
}

\author{
Nicholas Aigbobhiose Esene ${ }^{1}$, Simeon Ozuomba ${ }^{2,}$, Constance Kalu $^{2}$ \\ ${ }^{1}$ Directorate of Computer Services, University of Uyo, UNIUYO Uyo, AkwaIbom, Nigeria \\ ${ }^{2}$ Department of Electrical/Electronic and Computer Engineering, University of Uyo, UNIUYO Uyo, AkwaIbom, Nigeria
}

\section{Email address:}

niquekae@yahoo.com(N. A. Esene), simeonoz@yahoo.com(S. Ozuomba), constkay4@yahoo.com(C. Kalu)

\section{To cite this article:}

Nicholas Aigbobhiose Esene, Simeon Ozuomba, Constance Kalu. Community Informatics Social E-Learning Network: A Case Study of Nigeria. Software Engineering. Vol. 1, No. 3, 2013, pp. 13-21. doi: 10.11648/j.se.20130103.11

\begin{abstract}
Over the last few decades, the quality of education in Nigeria has declined leading to unacceptable low academic performance, high level of functional illiteracy, growing population of unemployable graduates. This paper presents Community Informatics Social E-learning Network (CISEN) that uses a community-based approach to identify and address the challenges facing education in the various communities across Nigeria. The CISEN uses an online GeoHubNet Community Structure (GCS) to organize the geo-communities in the various states of Nigeria. The CISEN focuses on bringing together the stakeholders in each local community to create awareness, identify issues pertaining to education, develop appropriate educational program that will address the issues raised and improve the quality of education in the local communities. Furthermore, the CISEN provides a framework for evaluation of the academic performance of the pupils and students on a continuous basis. CISEN also has mechanism for impact assessment of the system on the quality of education in those local communities it supports.
\end{abstract}

Keywords: Community Informatics, GeoHubNet, Education, Functional Illiteracy, Community Hub, Learning Process, Quality of Education

\section{Introduction}

Over the last few decades, the quality of education in Nigeria has continued to decline leading to growing population of unemployable graduates and increasing incidence of functional illiteracy across the nation. Several attempts have been made to address the situation but the success recorded so far is insignificant compared to the level of decadence in the quality of education in the same period. Basically quality education encompasses people who are healthy, well-nourished and ready to participate and learn, supported in learning by their families and communities, environments which are conducive for learning, contents which reflects the correct/upgraded curricula and materials and processes to evaluate and enhance teaching performance[1]. Given that different communities face different forms of challenges with respect to various aspect of quality education, it requires an innovative community-based approach to tackle the problem. In this paper, Community Informatics Social E-learning Network (CISEN) is proposed for improving the quality of education in Nigeria.
According to Gurstien [2], Community informatics (CI) is the study and application of ICTs to enable community processes such as community development. CI for education includes improvement in quality of education through ICT-enabled community collective process. Similarly, social e-learning entails incorporating social networking technology into E-learning system such that the social network tools and strategies can be used to enhance teaching and learning processes. CISEN is a facilitator-coordinated community-based social e-learning network that uses an online GeoHubNet Community Structure (GCS) to organize the geo-communities in the various states in Nigeria. The GCS enables the facilitator to build and manage active community learning networks and functional community education hub for each local community across the nation.

The community education hub provides room for facilitated community volunteered information system. Through this mechanism, the challenges and needs of the community in respect to education are identified and made visible and accessible on the online community education hub. At the same time, the CISEN makes room for 
corporate social responsibility intervention, government intervention and other sponsors and volunteered resources and services that are targeting at addressing those identified challenges and needs of the community. In addition, impact assessment mechanism is also built into the system for regular evaluation and reporting of the impact of the system on quality of education in the communities it supports.

Finally, this paper is arranged into sections such that section two presents a review of relevant literature. The methodology used is presented in section three along with the GeoHubNet Community Structure and the Community Education Hub. Lastly in section four, conclusion and recommendation for further research are presented.

\section{Review of Related Works}

\subsection{Education and Indices of Quality Education}

Education, according to English dictionary is "the process of acquiring knowledge and the theory of teaching and learning". In addition, education can be said to be "learning which is training and bringing up" Kaita [3]. Okafor [4] views education as a process of acculturation through which the individual is helped to develop and maximize his potentials and to use them when necessary, for the right reason and to be self-fulfilled. In this wise, quality of education can be said to be declining if it lacks the much desired outcomes. Bamisaiye [5] highlighted productivity of the educational system and the factors-inputs as the indices for measuring quality education. Productivity can be described as a ratio of inputs to outputs variables both in terms of quality and quantity.

Human and non-human inputs can be used in an educational system to produce desired output after going through a teaching and learning process. When such inputs are periodically measured in relation to the desired outputs using various techniques, the result obtained would be referred to as the productivity of the system. Factors-inputs indices include the following, Bamisaiye [5]:

- quantity and quality of inputs to education

- relevant curriculum

- appropriate teaching methods and the quality of teaching aids

- $\quad$ adequate and suitable infrastructural facilities

- $\quad$ students-teacher ratios and students-classroom ratios

- $\quad$ planning, administration and efficiency of inspection and supervision

- $\quad$ availability of suitable textbooks, well equipped library and resource centers for teachers and students

- the proportion of the trained men and women in the teaching force

- continuous assessment of learning activities and experiences

- $\quad$ reliability of examinations in use

- the quality of learning that is achieved

- $\quad$ parents' positive or negative attitudes to education

- cultural and religious views in the local community
- $\quad$ and the living levels of children's families, their health and nutrition.

Longe [6] pointed out that quality education involves measuring outputs from the education system and secondly examining the educational processes which produce these outputs. Quality of education can be determined from the input side such as students' capacity and motivation to learn and the curriculum or the subjects to be learned. Babalola [7]. In addition, the effective performance of the outputs in the competitive labor market, their impact on moral conduct and serviceability in the society are also indicators for measuring the quality of education. The feedback from the labor market and society generally is important to the education system for evaluation of both the educational processes and outputs.

In Nigeria, one useful index for measuring the quality of education is based on the measurement of students' performance overtime. This suggests that the success of any educational system or policy can be determined by the performances of the learners over a stipulated period of time. This idea can be called summative evaluation where evaluation is conducted at the end of a long period of study, which is cumulative, comprehensive, valid and reliable. Hopkins [8]. Accordingly, the major indices used in the Nigerian context are usually the results of examinations organized by examination bodies such as the West African Examinations Council (WAEC) and the National Examinations Council (NECO) which conduct certification examinations for Senior Secondary School students. Also, the functional literacy of graduates is an index for measuring quality of education in higher institutions. With the evaluation of the results publish over a period and adequate comparisons, the quality can be measured to determine the extent of decline. Furthermore, the ability of graduates of university to have the requisite industrial skills and technical "know-how" when employed is also an index to measure quality education.

\subsection{Challenges of Education in Nigeria}

The challenges in achieving quality education in Nigeria are numerous. According to Abodomu [9], many of the schools, most especially the public institutions lack infrastructures, books and other instructional materials. Onyike [10] noted that education in Nigeria has problem of shortage of teaching aids and unmotivated teachers. Ochuba [11] blames inspectors of schools for poor standards of education. The standard of education was continually declining due to low quality of supervision and inspection. Majidadi [12] explained that the total absence of the application of instructional material or poor use of it in teaching English language has a negative impact on learners. Lance [13] demonstrated that inadequate materials in school's libraries lowered the grades of students' performances whereas schools that have adequate materials have improved performance in their grades.

However, absence of instructional materials (language laboratory, audio - visual aid) leads to lower students' academic performance in teaching language subjects. Alaezi 
[14]. Also, Orkaa [15] stressed that these challenges are because students are refusing to subject themselves to studying. He said "they rather use fraudulent means and engage in examination malpractices, instead of studying. In 1976, Nigeria launched the Universal Primary Education (UPE). Regrettably, the program failed due to lack of funds. UNESCO stipulates a minimum of $26 \%$ of national budget. In 1999, Nigeria again launched the Universal Basic Education (UBE). The greatest challenge to UBE is the underfunding of the educational section which is still far below the standard set by the United Nations Educational, Scientific and Cultural Organization (UNESCO).

\subsection{Community Informatics and Social Network}

Keeble and Loader [16] describe Community Informatics as a "multidisciplinary field for the investigation and development of the social and cultural factors shaping the development and diffusion of new ICTs and its effects upon community development, regeneration and sustainability."Community Informatics in the area of education can be used in providing communities (villages, small towns, settlements and hamlets) with the means (manpower, skills, resources, funding) to address community-defined challenges as it relates to education.

Research findings indicate that social networks allow for interconnection and interaction of large number of people and communities, encourage collaboration and discussion of learning materials, and promote immediate sharing and development of text, audio, and visual contents (Rosen [17]). According to Mayfield [18] social network is characterized by user participation, openness, conversation, community, and connectedness. Social network serve as a platform to interact, share information, resources and ideas using social networking tools such as chat, messaging, video, email and discussion groups.

\subsection{Social E-Learning}

E-learning is teaching and learning that are delivered, supported, and enhanced through the use of digital technologies and social media. In this case social technologies are used to disseminate knowledge to enhance the traditional face-to-face teaching and learning methods. Also, Social E-Learning can be defined as incorporating e-learning into a social network such that the tools available in the social network for interconnectivity and interactivity can be used to enhance teaching and learning processes.

\section{Research Methodology}

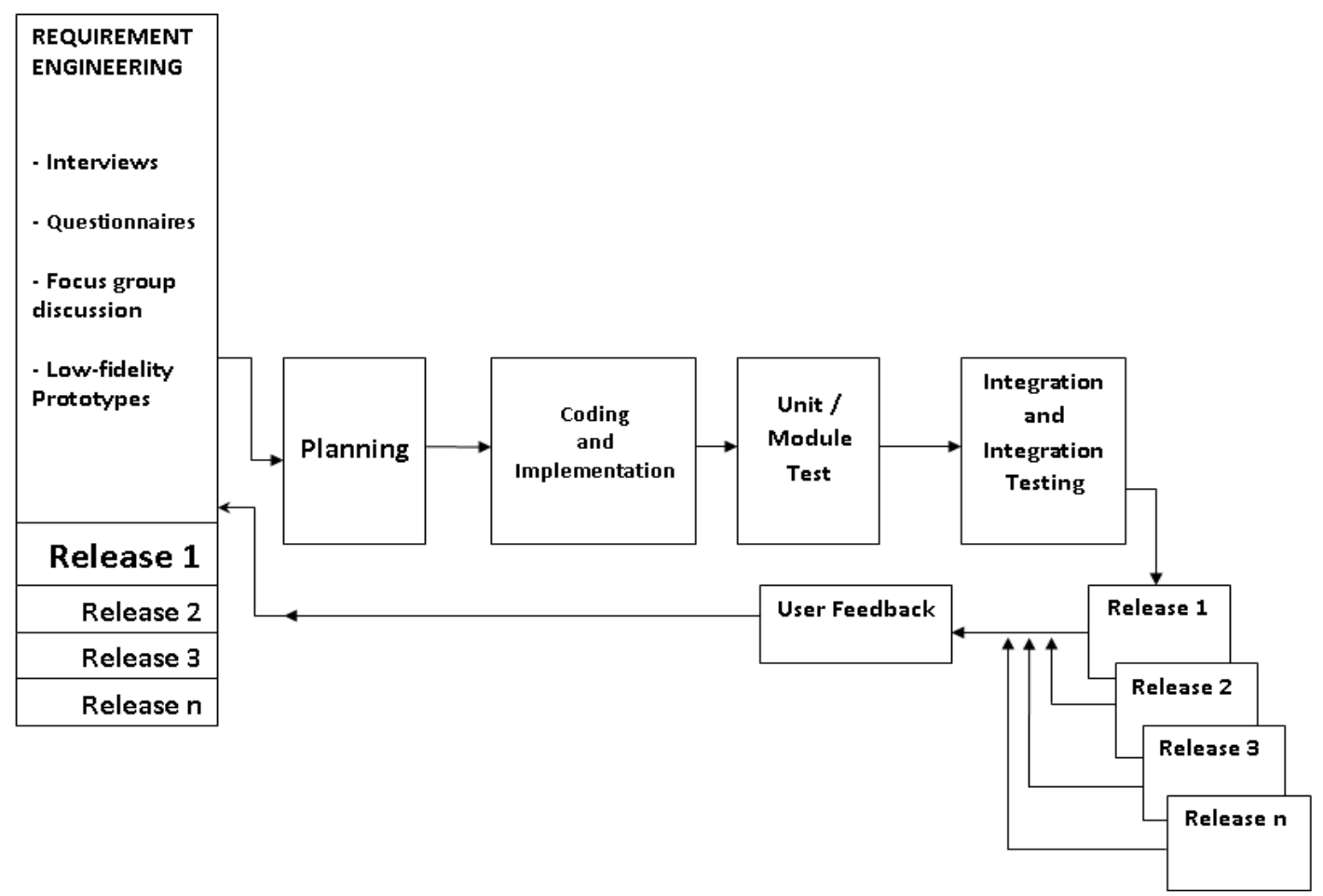

Figure 3.1. Participatory or Community-Centered Engineering (P-CCE) Methodology

The work entailed in this paper is the development of a system for improving the quality of education in Nigeria through the use of Community Informatics Social E-Learning Network (CISEN). User Centered Engineering (UCE) method called Participatory or Community-Centered Engineering (P-CCE) of Fig. 3.1 was used to develop the system. The P-CCE approach is both participatory and evolutionary. During the requirement engineering process, user and system requirements were acquired through the use of interviews, questionnaires and low fidelity prototypes. The bulk of the requirements obtained were from local community groups, schools and supervisors of education 
process and institutions in selected communities across the country. Thereafter, a requirement specification document was produced and then used to engage the stakeholders in the community for feedbacks which were used to modify the requirements until it meets the community expectations. The same approach was used to develop and evaluate the CISEN for improving the quality of education in each of the local communities involved in the system implementation.

\subsection{The Online Community Structure for the CISEN}

The paper adopted the online GeoHubNet community structure (Fig. 3.2) developed by Ozuomba et al. [19].

The GeoHubNet is used to organize the online communities according to certain existing geopolitical divisions such as nationwide, statewide, regional or citywide geo-communities. Fig. 3.2 shows a statewide
GeoHubNet structure. Inside the statewide GeoHubNet structure are regional geo-communities representing citywide, senatorial or local government geo-communities. Within each regional local community are local groups, institutions and individuals who are members of that online community. Each regional geo-community has a set of facilitators and possibly along with co-facilitators that moderate the interconnection and interaction of the members in that regional community. The facilitators also conduct the regional community network weaving. The collection of all the regional community facilitators in a state make up another network called the HubNet. The HubNet in this case are actually the local community organization that champions the community improvement program. In other words, the HubNet is the facilitator organization for the CISEN.

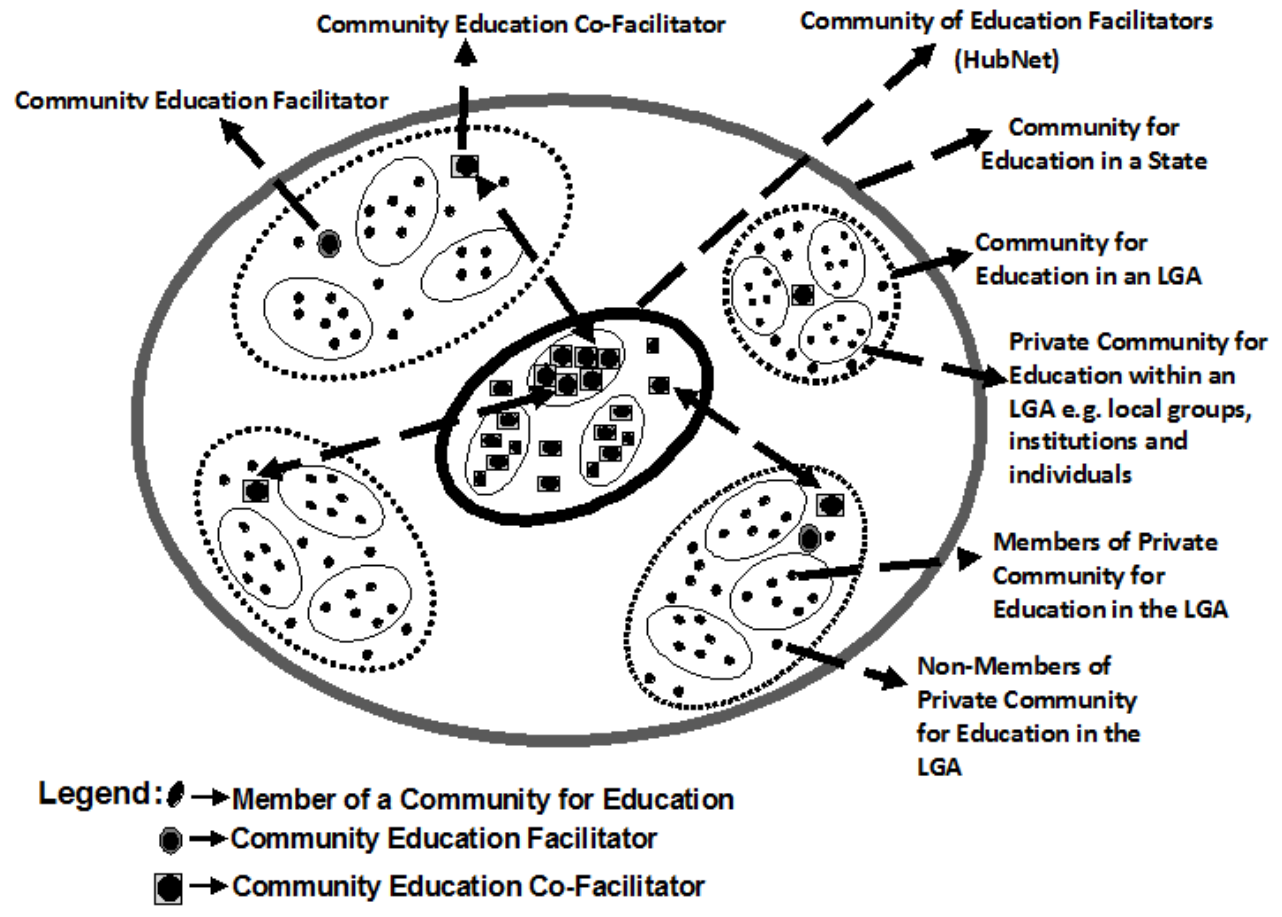

Figure 3.2. Statewide GeoHubNet Community Structure.

\subsection{The CISEN Online Community Hub}

In order to ensure active participation of local community members and other educational stakeholders in improving the quality of education in selected communities in Nigeria, the CISEN provides online geo-community education hub [19] for each of the local communities it supports. The components of the online geo-community hub are shown in Fig. 3.3.

With respect to the online GCS, the online geo-community is created for each local community in the various states in Nigeria. Then, the facilitator builds online community education hub on each of the online geo-community it has created for each of the local community it supports.
The online geo-community education hub is basically a one spot or virtual space on the internet where the scholarships, facilities, schools, opportunities, local groups, local information and discussions, etc. that are relevant for improving the quality of education in each local community are made visible and accessible. The community education hub also makes provision for a Volunteer Management System (VMS), strategic community network weaving and Facilitated Community Volunteer Information System (FCVIS). In addition, the system uses Google Maps mash-up applications to support Facilitated Volunteer Geographic Information (FVGI) for mapping community education resources. The Facilitated Community Volunteer Information System (FCVIS) and the Facilitated Volunteer Geographic Information (FVGI) with Google 
Maps mash-up applications enable facilitated user-generated information; educational resource mapping; social validation of contents and issues; request for community support; request for sponsorship intervention and opportunity for volunteering resources and services.

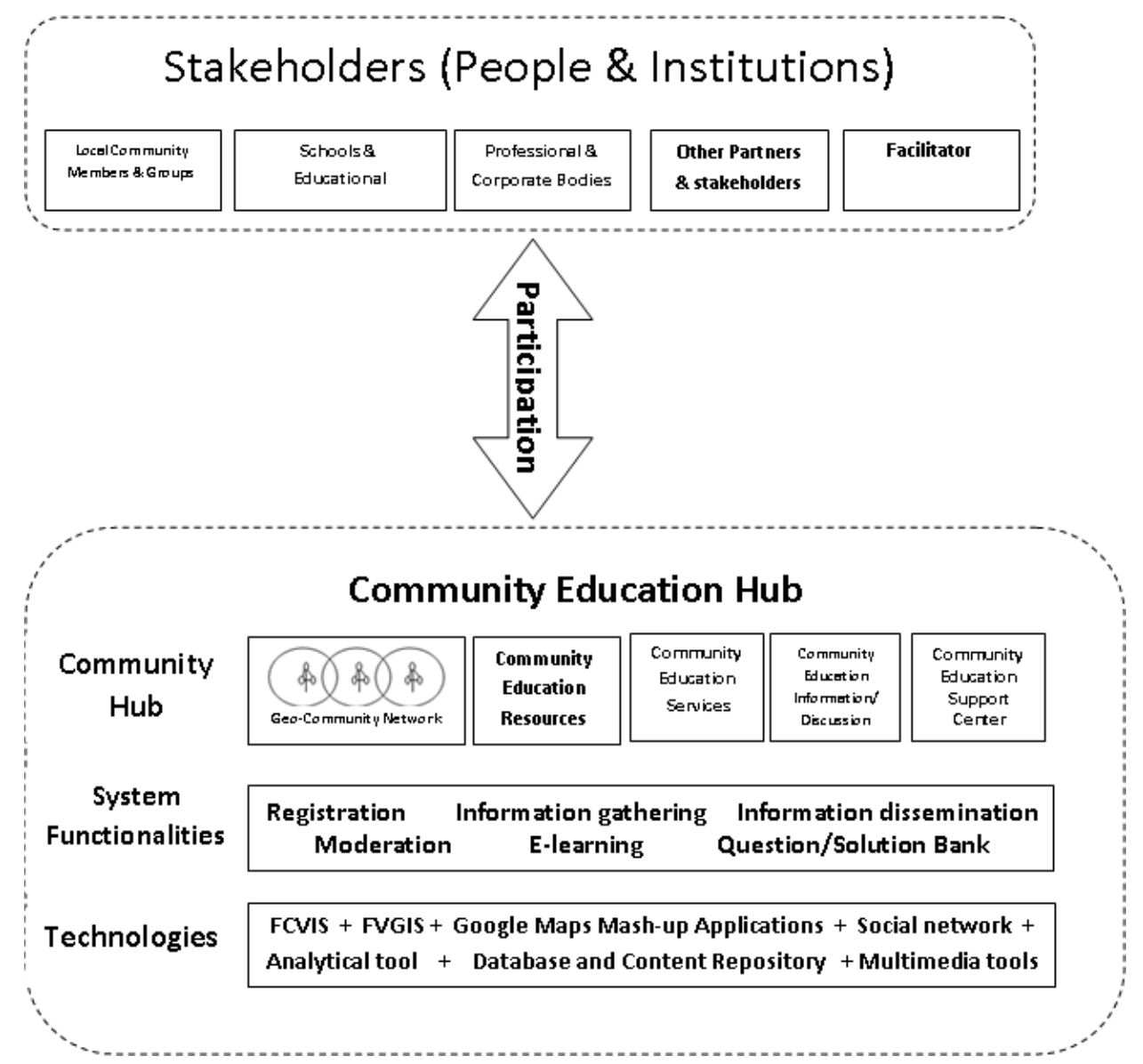

LEGEND:

FCVIS: Facilitated Community Volunteer Information System

FVGIS: Facilitated Community Geographic Information System

Figure 3.3. Model for the CISEN Geo-community Education Hub

The Volunteer Management System (VMS) enable community members, groups and institutions to volunteer resources, services etc. targeted at improving the quality of education in the community. The VMS enables the facilitator to coordinate the volunteers, volunteered items, as well as the beneficiaries of those volunteered resource and services. In addition, the CISEN has robust e-learning features which allow community access to downloadable materials in various formats. Social networking tools are also incorporated in the CISEN to allow for teaching and learning management; registration and management of online community members, etc.

\subsection{Functional Decomposition of the System}

The following components would be used to implement the modules in the CISEN incrementally and evaluated until it meets the community desired educational objectives.

1) The online social network comprising the community education hub network structure (framework) registration of members and active community groups.

2) Identify and capturing community challenges through facilitated community volunteer information system (FCVIS).

3) Sponsorship, Volunteer and Community Support Facilities (SVCSF)

4) The Volunteer Management System (VMS)

5) E-learning (Question and Solution Bank, Book Chapter review, plagiarism checking, downloadable resources, quiz, collaborative research).

6) Community Education Information and Discussion forum (CEIDF)

7) Community Education support (CES) center / Feedback and Survey for Evaluation (FSE).

With respect to the CISEN online community hub of Fig. 3.3, the modules will be developed as shown in Fig. 3.4a and the functional decomposition of the modules is presented in Fig 3.4b. The complete system development and support methodology is present in Fig. 3.5. 
The CISEN modules in Fig. 3.4a are independent of one another and are loosely coupled meaning a failure, downtime or system fault in one would not affect the functionalities of any of the others and each can be accessed individual or in a group without necessitating feedback or input from the others. The functional decomposition of each of the modules is shown below;

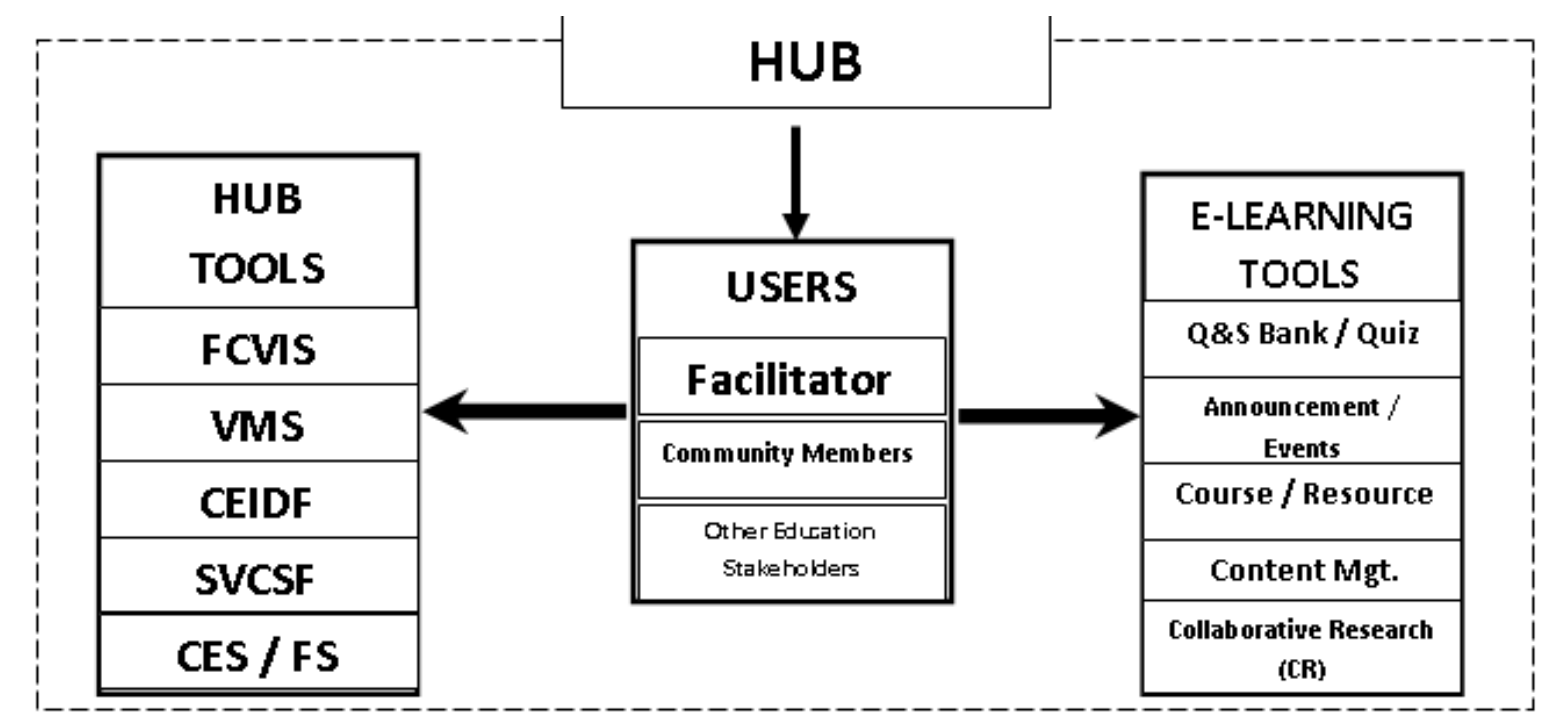

Figure 3.4a. The modules in the Community Informatics Social e-learning System

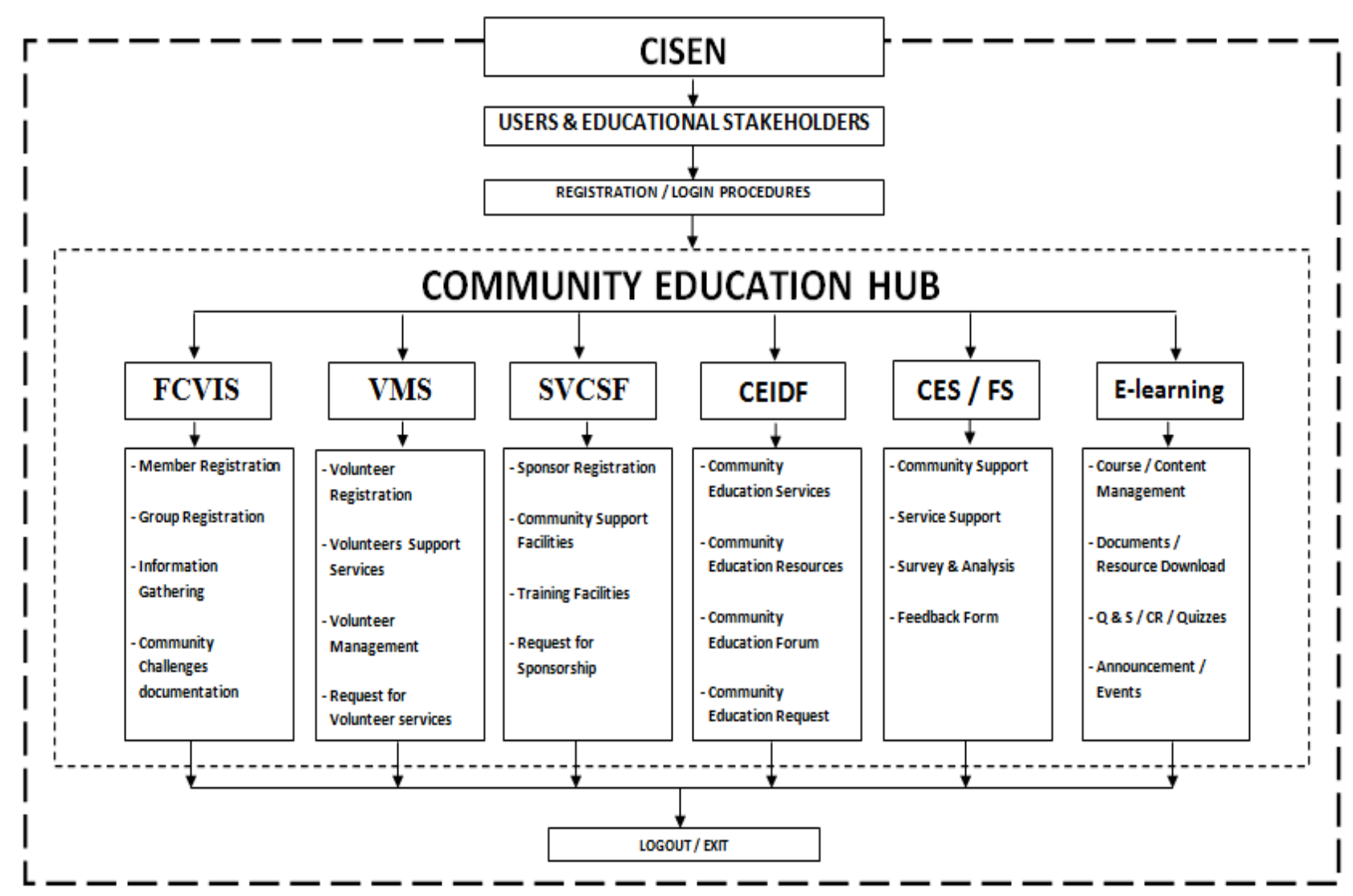

Figure 3.4b. Functional decomposition of the CISEN 


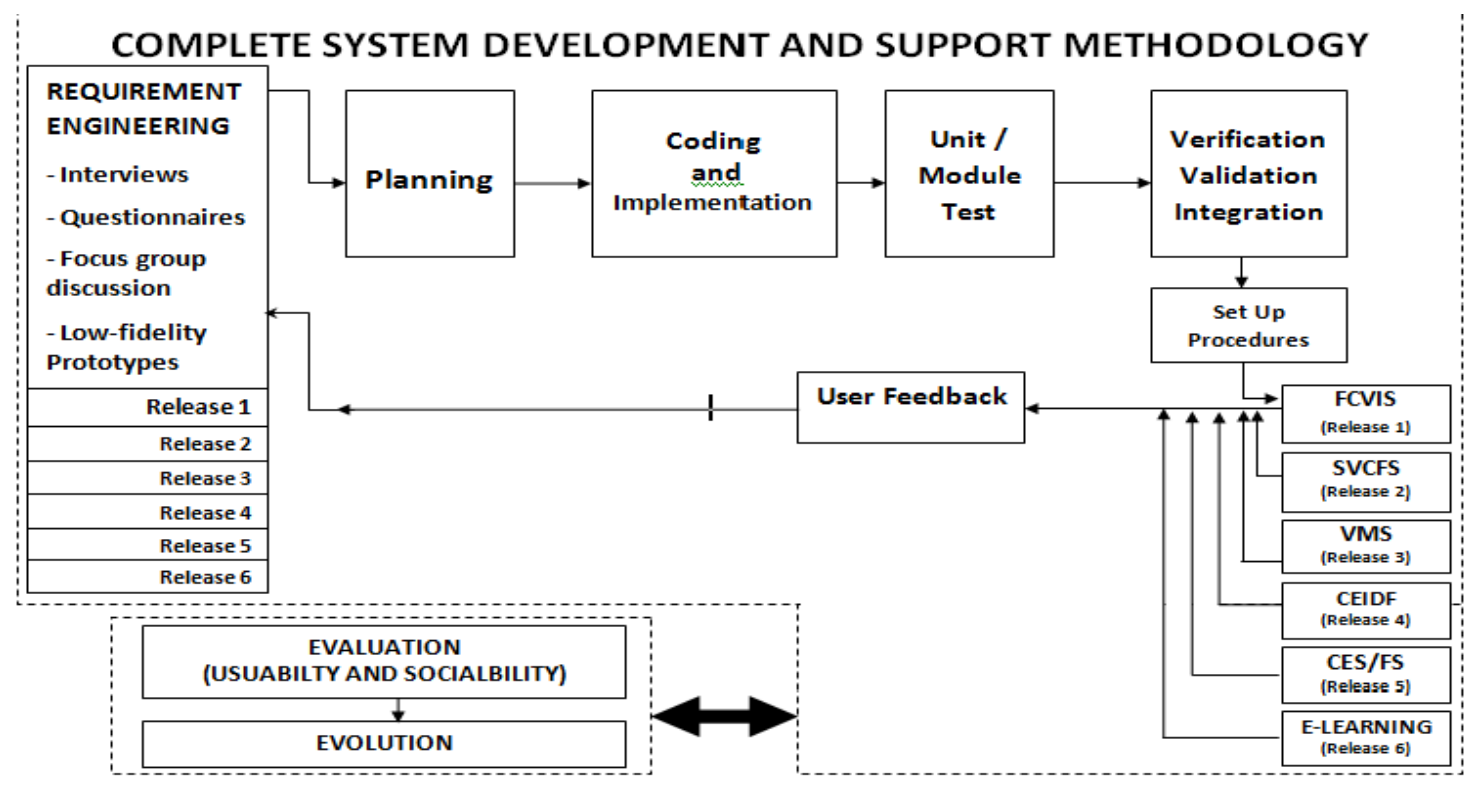

Figure 3.5. Enhanced Incremental P-CCE Method for the CISEN

\subsection{The Community Hub Structure}

The first stage is the Requirement engineering process which involves elicitation and information gathering that were analyzed and triangulated and used to prepare the requirement specification document which is needed in the planning stage of the incremental process. The user requirements were obtained by identifying and engaging the various stakeholders intended to use the system using mainly interviews, observation, questionnaire, focus group discussion, brainstorming and low-fidelity prototyping as shown in Fig. 3.6. A User Participatory Evolutionary Requirement Engineering Process (UPEREP) was produced and adopted at the end of this stage.

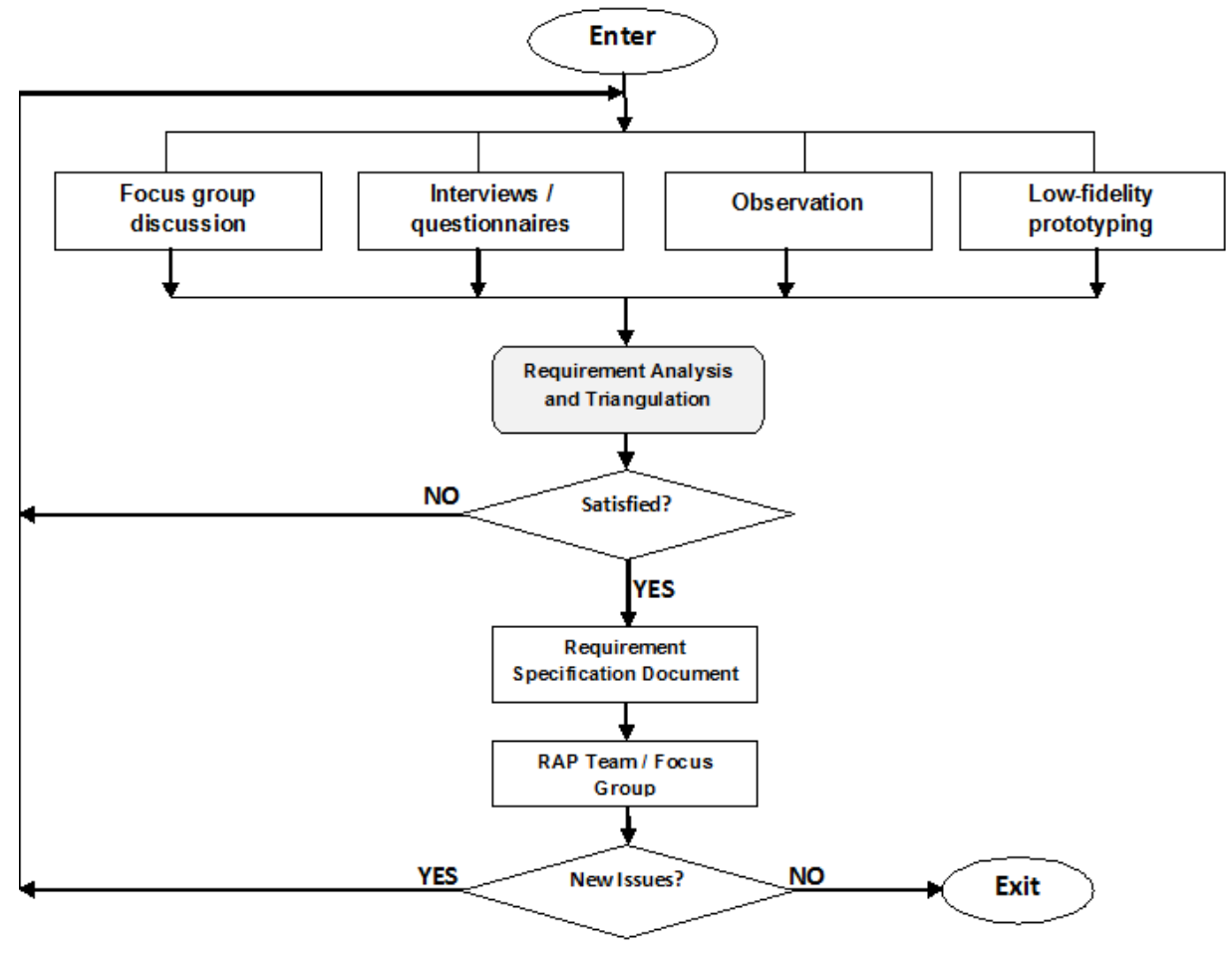

Figure 3.6. UPEREP Model for the CISEN

As shown in Fig. 3.6, the requirement elicitation begins with focus group discussions, guided interviews / questionnaires, observations in the community and low-fidelity prototyping. These techniques were employed and data collected, analyzed and triangulated to produce the requirement specification document. However, if there is 
ambiguity or disparity in the data collected, it involves going back to the requirement elicitation process.

The Rapid Assessment Process (RAP) and focus groups discussions are used together most of the time in data analysis and investigation of the requirement specification document. The RAP approach involves strong collaboration with domain experts in the field of education to verify, authenticate and validate the requirements specification document for education in the community.

\subsection{Functional Requirements of the System}

The first stage is the Requirement engineering process which involves elicitation and information gathering that were analyzed and triangulated and used to prepare the requirement specification document which is needed in the planning stage of the incremental process. The user requirements were obtained by identifying and engaging the various stakeholders intended to use the system using mainly interviews, observation, questionnaire, focus group discussion, brainstorming and low-fidelity prototyping as shown in Fig. 3.6. A User Participatory Evolutionary Requirement Engineering Process (UPEREP) was produced and adopted at the end of this stage.

\subsubsection{FCVIS (Facilitated Community Volunteer Information System)}

This module captures the educational challenges faced by the community. This is done through a facilitated volunteer mechanism. The system provides a platform for community members to register their challenges with respect to education. A facilitate moderates these inputs and groups them into categories.

\subsubsection{SVCSF (Sponsorship, Volunteer and Community Support Facilities)}

This system module enables users to sponsor or volunteer to provide support services to community challenges already registered. It makes visible all the community challenges based on categories such as training facilities, teaching aids, etc. It also provides a platform to register community support facilities.

\subsubsection{VMS (Volunteer Management System)}

This module manages volunteer services in the system. It makes the volunteer services visible such that community members can easily access and contact the volunteers for support or sponsorship. The system also moderates the volunteer services to match or suit the community pressing educational needs according to their areas of interest.

\subsubsection{E-learning}

This module covers all e-learning functionalities in the system. It serves as a robust learning management system. The module has functionalities to check plagiarism in submitted documents (.doc, .docx, pdf, ppt, txt, cpp, java and odt-open office formats). The system provides access to moderated question and solution bank and book chapter review. The system also makes provision to deliver course/learning contents synchronous or asynchronous with ready access to downloadable resources such as e-books, videos and audios in various formats and learning and teaching materials. The system provides a collaborative platform for research, learning and solving educational issues and challenges.

\subsubsection{CEIDF (Community Education Information and Discussion Forum)}

This is a forum and discussion board where the community members and other stakeholders meet to brainstorm and exchange ideas on issues geared at improving the quality of education in the community. Areas of interests may include government policies, educational standards, curriculum development, sponsorship or corporate social responsibility. The forum serves as a platform for stakeholders of the system to raise concern and proffer solutions which are made visible to the general public.

\subsubsection{CES (Community Education Support Center) / FSE (Feedback and Survey for Evaluation)}

This module provides an online survey for community members to assess the impact of the system in the community. It also provides a support center for questions and enquiries of the system. The system also has a feedback form to enable users to express their opinion on the impact of the system on the community. The information are collated and used for evaluation and as a tool for decision support.

\section{Conclusion}

This paper presented CISEN for improving the quality of education in various local communities across Nigeria. The problems posed by the decline in the quality of education in Nigeria were also outlined in this work. The CISEN was developed using an Incremental Participatory or Community Centered Engineering (P-CCE) approach while the UPEREP Model was used for the requirement engineering. An online community architecture called GeoHubNet was also employed to create and manage the online community and the corresponding community education hub. Furthermore, the functional decomposition of the modules of the CISEN and the description of the modules were presented with diagrams to demonstrate the usefulness of the CISEN in improving the quality of education in each of the local communities it would be implemented.

\section{References}

[1] UNICEF. Defining Quality in Education. Document No. UNICEF/PD/ED/00/02. Working Paper Series, Education Section, Programme Division. New York, NY: Author, 2000.

[2] M. Gurstein. Community informatics: enabling communities with communication technologies. Hershey, PA: Idea Group Publishing, 2000. 
[3] M. H.Kaita. "Women Education in Nigeria". Adaralegbe A. (ed) A Philosophy of Nigeria Education. Ibadan. Heinemann Education Books (Nig) Ltd, 1969.

[4] F. Okafor . Nigeria teacher education: A search for new direction. Enugu: Fourth Dimension Publishers Ltd, 1988.

[5] E. A.Bamisaiye. Qualitative primary and secondary education in Nigeria: implications for implementation. Ilorin journal of education 3(1), 15books Ltd, 1983.

[6] R. S.Longe. Investment in Nigerian education: relevance, quality and governance at the eve of the third millennium. An inaugural lecture, UI, 1999.

[7] J. B. Babalola. Revitalizing quality higher education in Nigeria: options and strategies. In J. B. Babalola, G. O. Akpa, A. O. Ayeni and S. O. Adedeji: access, equity and quality in higher education. NAEAP publication, 2007.

[8] D. Hopkins. Evaluation for School Development. Buckingham, England: OpenEd. (2004). Administering education in Nigeria: A recipe: Ibadan: Heinemann,1997.

[9] E. O. Abodomu. Nigerian Education system at the crossroad, fifty years after independence. A paper presented at the 5th National conference of school of Arts and social sciences, College of Education, Oju, 2010.

[10] M.O.Onyike. Poverty, Education and sustainable educational development in Nigeria. A paper presented at the 5th National conference of school of Arts and social sciences, College of Education, Oju, 2010.

[11] V.O. Ochuba. Improving the quality of education in Nigeria through effective inspection of schools. Paper presented to the Annual Meeting of the American Education Research Association, New Orleans L.A. April, 5-6, 2009.

[12] J.H. Majidadi. The role of English in Nigerian Education. University of Jos University press, 1972.

[13] K. C. Lance. The impact of school library media centers on academic achievement. Washington, DC: U.S. Department of Education Office of Educational Research and Improvement, 1994.

[14] O. Alaezi. Groundwork of teaching strategies in Nigeria.Feb Anieh Limited.Jos-Nigeria, 1990.

[15] D.Orkaa. Threat to education in Nigeria: The voice Newspaper. Benue printing and publication Vol. 4 No. 615638. Jonah Jang Crescent, Makurdi Benue State Nigeria, Aug. 2010.

[16] L.Keeble \& B. D. Loader (Eds.). Community informatics: Shaping computer-mediated social relations. London: Routledge, 2001.

[17] L. D. Rosen. Rewired: Understanding the iGeneration and the way they learn. New York: Palgrave Macmillan, 2010.

[18] A.Mayfield. Whatis social media? iCrossing. Updated 01 Aug, $2008 . \quad$ Retrieved from:http://www.icrossing.co.uk/fileadmin/uploads/eBooks/ What_is_Social_Media_iCrossing_ebook.pdf, 2006.

[19] S. Ozuomba, A. G. Chukwudebe, K. Felix Opara and M. Ndinechi: Geohubnet: The Online Community Structure For Community Informatics Social Network. Retrieved from http://epromac.com.ng/onddc/papers/GEOHUBNET.pdf, 2013, unpublished. 